\title{
A CADAVERIC STUDY OF VARIABILITY IN THE ORIGIN OF OBTU-
} RATOR ARTERY

\author{
Basavaraj Dhabale ${ }^{1}$, Santosh Kumar Mulage *2. \\ ${ }^{1}$ Assistant Professor, Department of Anatomy, Karwar Institute of Medical Sciences, Karwar, \\ Karnataka, India. \\ ${ }^{* 2}$ Associate Professor- Department of Anatomy, Gulbarga Institute of Medical Sciences, Gulbarga, \\ Karnataka, India.
}

\section{ABSTRACT}

Background: The origin of obturator artery $(O A)$ is important clinically because of its vascular role. The OA is one of the branches of the anterior division of the internal iliac artery. The source of OA has been documented from all possible neighboring arteries. So the course and ramification of the OA have received attention for gynecologists and surgeons.

Materials and Methods: Study was conducted on 30 bisected pelvises specimens in Department of Anatomy, Gulbarga Institute of medical sciences, Gulbarga The pattern of origin of the obturator artery was identified. The obturator artery was traced from its origin to it extends till the obturator foramen.

Results: In $80 \%$ (24 sides) the origin of obturator artery was from the internal iliac artery. In $76.7 \%$ ( 23 specimens), the obturator artery was originated from anterior division of internal iliac artery. Out of these, $46.7 \%$ ( 14 specimens), the obturator artery arouses as a single and direct branch of the anterior division of the internal iliac artery while variation in its origin as a common trunk was observed in $30 \%$ ( 9 specimens). In $20 \%$ ( 6 sides), it arouses from the external iliac artery i.e. from an inferior epigastric artery.

Conclusion: Anomalous origin of OA may injure during surgical repair of hernia and fracture of superior ramus of pubis. The sound knowledge on anatomical variations of OA is very important to the general and vascular surgeons for successful outcome of the above mentioned surgical procedures and will help them to avoid unnecessary complication.

KEY WORDS: Internal iliac artery, Anterior Division, Pelvic vessels, Inferior epigastric artery.

Address for Correspondence: Dr. Santosh Kumar Mulage, Associate Professor, Department of Anatomy, Gulbarga Institute of Medical Sciences, Gulbarga.585101, Karnataka, India.

Mob: 9449302888. E-Mail: drsantu77@gmail.com

Access this Article online

Quick Response code

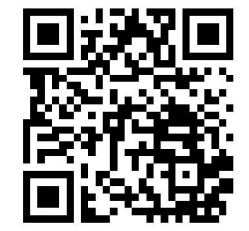

DOI: $10.16965 /$ ijar.2018.124

Journal Information

International Journal of Anatomy and Research

ICV for 2016 ISSN (E) 2321-4287 | ISSN (P) 2321-8967

90.30 https://www.ijmhr.org/ijar.htm DOI-Prefix: https://dx.doi.org/10.16965/ijar

Article Information

Received: 30 Jan 2018

Peer Review: 30 Jan 2018

Revised: None
Accepted: 07 Mar 2018

Published (O): 05 Apr 2018

Published (P): 05 Apr 2018

\section{INTRODUCTION}

The retro pubic space is the most common targeted area for gynecologists and surgeons during intra-abdominal therapeutics procedures to avoid hemorrhagic complication. The origin of obturator artery (OA) is important clinically because of its vascular role. The OA is one of the branches of the anterior division of the internal iliac artery. It passes downwards on the lateral pelvic wall to reach and passes through the obturator foramen. It is the chief artery which supplies hip joint and muscles of adductor compartment as well as it gives branches to urinary bladder and twigs to ilium and pubis 
within pelvis [1].

The vascular variations of origin of OA have been well acknowledged in the literature. The source of OA has been documented from all possible neighboring arteries i.e. common iliac, external iliac or from any branch of the internal iliac in both sexes. So the course and ramification of the OA especially in the pelvis and retro pubic space have received attention for gynecologists and surgeons because the anomalous origin of $\mathrm{OA}$ and its variation are the main etiology of bleeding [2].

\section{MATERIALS AND METHODS}

Thirty formalin-fixed specimens were selected irrespective of side and sex from 50 human cadaveric bisected pelvises during the routine dissection in the Department of Anatomy, Gulbarga Institute of medical sciences, Gulbarga. The dissected method was employed for the study in each half of the pelvis. After the locating the common iliac artery, the branches of the internal and external iliac artery were dissected. The pattern of origin of the obturator artery was identified. The obturator artery was traced from its origin to it extends till the obturator foramen.

Statistical analysis: The data was entered and analyzed in Microsoft office excel 2007. The generated data was summarized as percentages.

Fig. 1: Dissection images and Schematic representation of variability of OA origin.
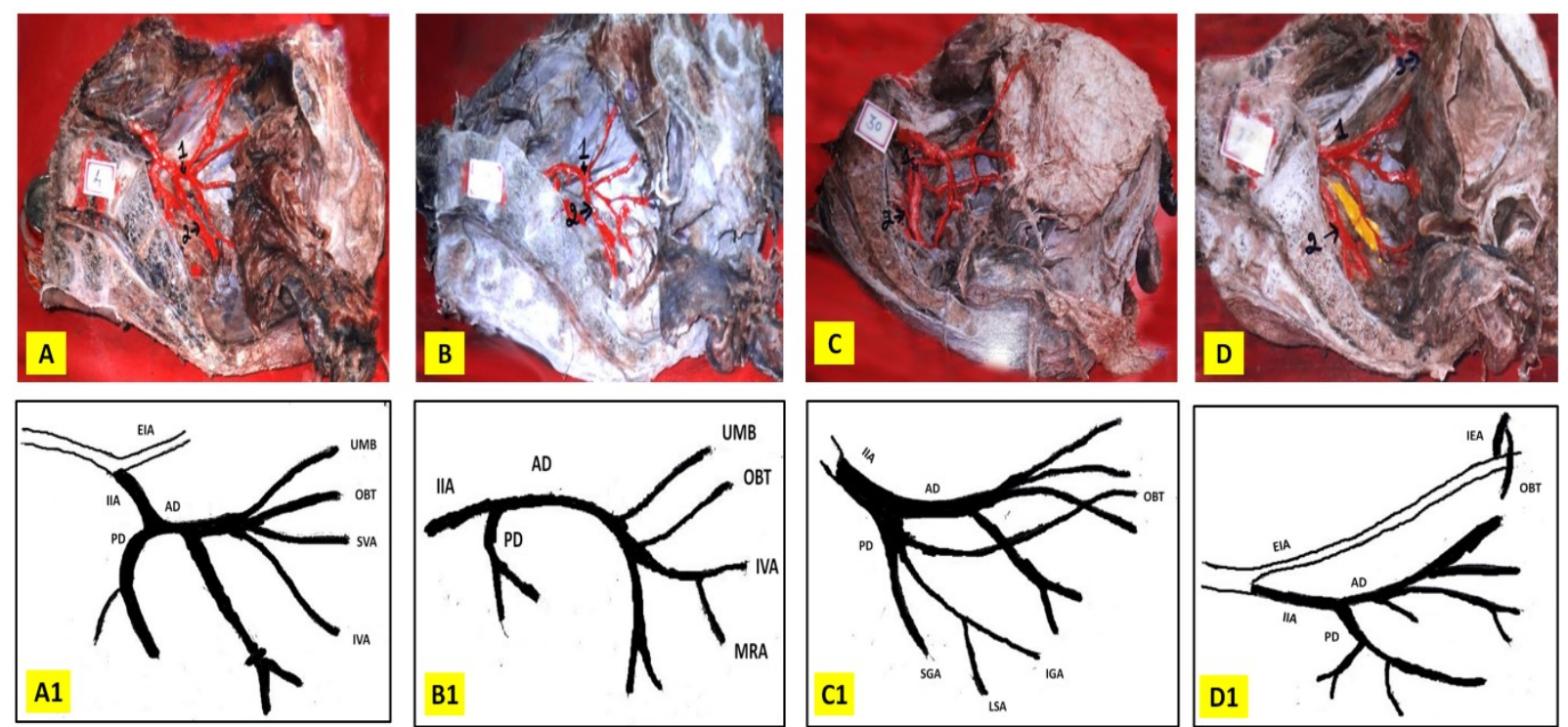

A) \& B) shows the origin of OA other than the anterior division proper, C) Shows the origin of OA from Posterior Division of IIA, D) shows the origin of OA from IEA. IIA- Internal iliac artery, EIA- External iliac artery, AD- Anterior Division, PD- Posterior Division, UMB-Umbilical artery, OBT- Obturator artery, SVA- Superior vesical artery, IVA- Inferior Vesical artery, MRA= Middle rectal artery, IEA- Inferior Epigastric artery 


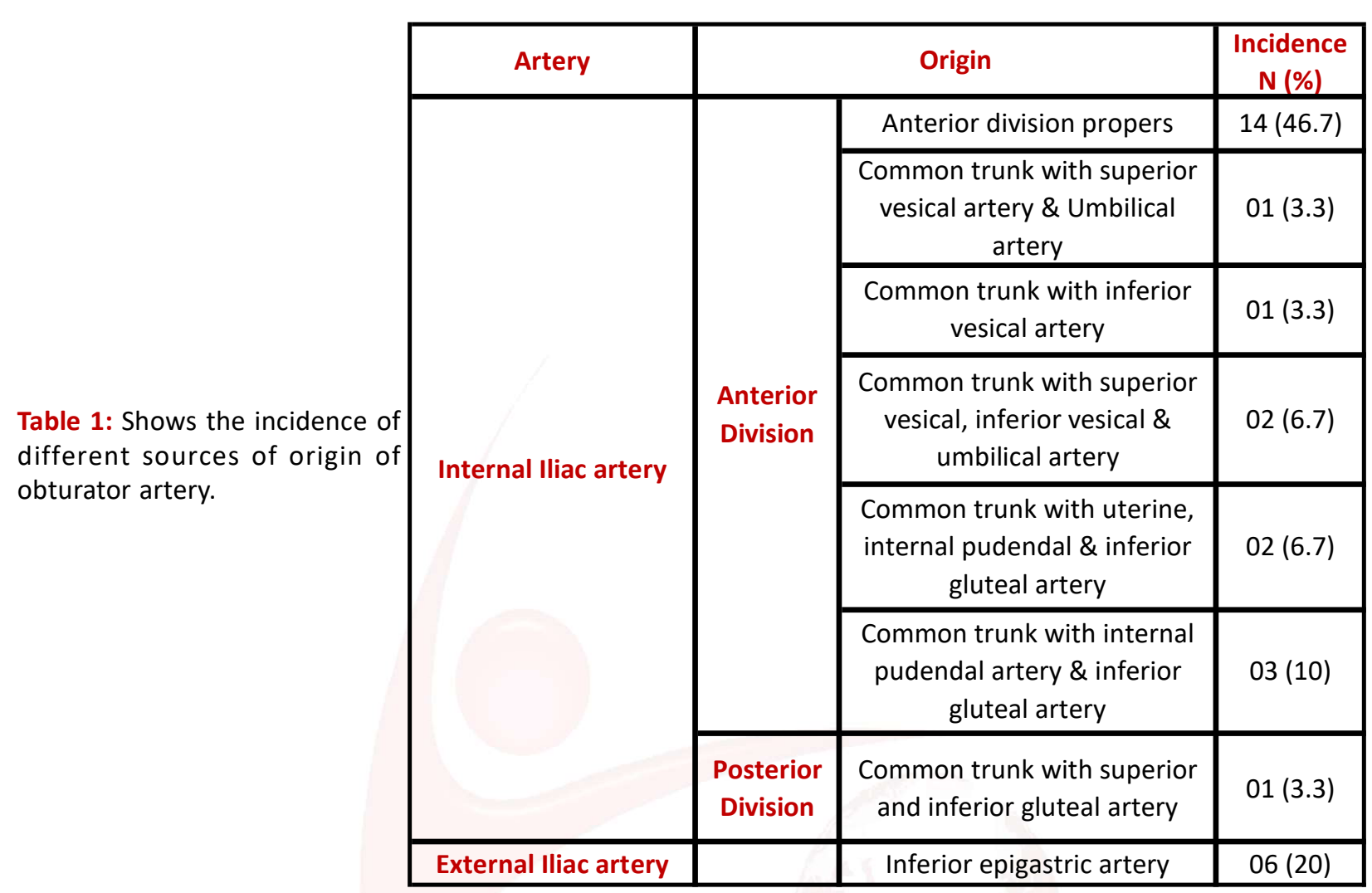

Table 2: Comparison of present study findings with the previous studies.

\begin{tabular}{|c|c|c|c|c|c|c|c|}
\hline \multirow{2}{*}{\multicolumn{2}{|c|}{ Origin }} & \multicolumn{6}{|c|}{ Authors (\%) } \\
\hline & & $\begin{array}{c}\text { Tirupathi Rao } \\
\text { et al. [4] }\end{array}$ & $\begin{array}{c}\text { Sakthivel } \\
\text { [5] }\end{array}$ & $\begin{array}{c}\text { Braithwaite } \\
\text { [6] }\end{array}$ & Pai [7] & $\begin{array}{c}\text { Kumari S } \\
\text { [8] }\end{array}$ & $\begin{array}{c}\text { Present } \\
\text { study }\end{array}$ \\
\hline \multirow{3}{*}{$\begin{array}{l}\text { Internal } \\
\text { Iliac artery }\end{array}$} & $\begin{array}{c}\text { Anterior Division } \\
\text { proper }\end{array}$ & 35.5 & 36.67 & 41.4 & 60 & 66 & 46.7 \\
\hline & $\begin{array}{c}\text { Other than Anterior } \\
\text { Division Proper }\end{array}$ & 22.43 & 0 & 18.5 & 0 & 3.3 & 30 \\
\hline & Posterior Division & 6.66 & 30 & 13.5 & 8 & 16.6 & 3.3 \\
\hline $\begin{array}{l}\text { External } \\
\text { Iliac Artery }\end{array}$ & $\begin{array}{l}\text { Inferior Epigastric } \\
\text { artery }\end{array}$ & 26.66 & 25 & 19.5 & 14 & 3.3 & 20 \\
\hline
\end{tabular}

origin of Obturator artery (OA) was from the anterior division of internal iliac artery (IIA) followed by the inferior epigastric artery (IEA).The variability of origin of obturator artery is summarized in Table 2. Dissection images and Schematic representation of variability of OA origin is depicted in the Figure 1.

\section{DISCUSSION}

The exposure to the lower abdominal region is important during various operative, diagnostic and intra-abdominal therapeutics procedures. The most common source of origin of obturator artery is a single branch arising from the anterior division of the internal iliac artery. However, variability in the origin of obturator artery had been documented from all possible neighboring arteries i.e. common iliac, external iliac or from any branch of the internal iliac in either sex [3]. The course and ramification of such variant vessels create an eye opener for the gynecologists and surgeons during intra-abdominal therapeutics procedures.

The incidence of obturator artery (OA) arising from the anterior division of internal iliac artery (IIA) in the literature varies from $35 \%$ to $66 \%$ [4-8]. The present study findings and the Previous studies findings on the variability of origin of obturator artery are summarized in Table 2.

In the present study, the incidence of obturator artery arising from the anterior division of internal iliac artery was found in $46.7 \%$ of specimens. Our finding was similar and close to Braithwaite et al who also reported in $41.4 \%$ of cases. [6]. But Kumari $S$ et al had reported the highest 
incidence in $66 \%$ of specimens [8]. Another study conducted by Tirupathi Rao et al reported the incidence of $O A$ arising from the anterior division of ILA in $35.5 \%$ which is significantly lower than our finding [4].

In our study, OA was arising from the posterior division of internal iliac artery (IIA) in $3.3 \%$ of specimens. It arises as common trunk along with superior and inferior gluteal artery. It was observed by previous authors to arise from the posterior division of internal iliac artery (IIA) varies from $6 \%-30 \%$ [4-8]. But the highest incidence was reported by the Sakthivel et al (30\%) [5]. In the present study, we have not documented the origin of OA directly from the common iliac artery and external iliac artery. But in literature, many have been reported the incidence of origin of OA from the external iliac artery. A study conducted by Tirupathi Rao et al reported the highest incidence of $\mathrm{OA}$ arouses from an external iliac artery in $8.8 \%$ specimens. Various other authors reported an incidence ranging from $1.1 \%$ - 9\% [4-9]

However, we document the percentage of obturator artery (OA) arising indirectly from the external iliac artery i.e from an inferior epigastric artery (IEA). This origin is documented as second most common variation in the present study. In our study, the incidence of OA arising from the IEA was found in $20 \%$. A similar finding was reported by Braithwaite et al and Sakthivel et al who had recorded the incidence of OA arising from the IEA in $19.5 \%$ and $25 \%$ respectively $[6,5]$. Another study conducted by Tirupathi Rao et al reported the incidence of OA arising from the IEA in $26.6 \%$ which is significantly higher than our finding [4] Additionally, other subvariants such as the common stem of OA with another branch of the anterior division of IIA were also observed in our study. Various authors reported an incidence of origin of OA other than anterior division ranging from $3.3 \%-22.43 \%$ [4-8].

In our study, the incidence of common stem of OA with superior vesical and umbilical artery was found in 1 specimen (3.3\%), with inferior vesical in 1 specimen (3.3\%), with superior vesical, inferior vesical \& umbilical artery in 2 specimens (6.7), with Common trunk with uterine, internal pudendal \& inferior gluteal artery in 2 specimens (6.7\%) and with Common trunk with internal pudendal artery \& inferior gluteal artery in 3 specimens (10\%). But the highest incidence was reported by the Tirupathi Rao(16.67\%) [8].

In the literature, the incidence of dual obturator artery or aberrant obturator artery was reported. Sonje et al observed the dual origin of obturator artery from external and internal iliac in $2.85 \%$ [9] while Braithwaite et al and Maneesha S were reported in $6.5 \%$ and $6.67 \%$ respectively $[6,11]$. Embryological explanation regarding the variation in the origin of obturator artery may be due to the unusual selection of channels from the primary capillaries consequences in forming the abnormal arterial patterns [3]. The most appropriate channels enlarges, whilst the others retract and disappear, thereby establishing the final arterial pattern and resulting in variation in the origin [12].

\section{CONCLUSION}

With the expansion of modern surgical procedures and investigatory techniques involved in obstetric procedures or urogenital interventions, it is necessary to understand the course and ramification of the vessels of the abdomen especially pelvis. Anomalous origin of OA may injure during surgical repair of hernia and fracture of superior ramus of pubis. Variability in the origin of OA may be a source for complication or misdiagnosis. The sound knowledge on anatomical variations of OA is very important for successful outcome of the above mentioned surgical procedures. This study will be of great use to the general and vascular surgeons and will help them to avoid unnecessary complication.

\section{ABBREVIATIONS}

OA- Obturator artery

IEA - Inferior epigastric artery

IIA - Internal iliac artery

EIA- External iliac artery

AD- Anterior Division,

PD- Posterior Division

UMB- Umbilical artery,

SVA- Superior vesical artery

IVA- Inferior Vesical artery

MRA- Middle rectal artery 


\section{Conflicts of Interests: None}

\section{REFERENCES}

[1]. Williams PL. Gray's Anatomy. The Anatomical Basis of Clinical Practice. 38 Ed. Edinburgh, Churchill Livingstone. 1995: 1560.

[2]. Condon, re. and Nyhus, Im. Complicaciones de la hérnia inguinal. $3 r d$ ed. In nyhus, Im. And condon, re. (eds). Hernia. 3rd ed. Philadelphia: lippincott, 1991.

[3]. Arey, L.B. The development of peripheral blood vessles. In the peripheral blood vessles (Ed Orbison J L \& Smith D E), 1-16, Baltimore: Wiliams and wilkins, 1963.

[4]. Tirupathi Rao V, Srinivasarao Y, Dorai Raj SJ. An anomalous origin of obturator artery and its clinical importance in humans. Int J Anat Res. 2013;1:26.

[5]. Sakthivel, Priyadarshini S. Variability of origin of Obturator artery and its clinical significance. Int J Anat Res 2015; 3(4): 1704-1709

[6]. Braithwaite JL. Variations in origin of parietal branches of internal iliac artery. J Anat. 1952; 86:423-30.
[7]. Pai MM, Krishnamurthy A, Prabhu LV, Pai MV, Kumar SA, Hadimani GA. Variability in the origin of the obturator artery. Clinics. 2009; 64(9):897-901.

[8]. Kumari S, Gowda MT. A study of variations of origin of obturator artery: Review in south Indian population. Journal of the Anatomical Society of India. 2016 Aug 31;65:S1-4.

[9]. Biswas S, Bandopadyay M, Adhikari A. Variation of origin of obturator artery in eastern Indian population. J Anat Soc India. 2010; 59(2):168-172.

[10]. Sonje PD, Vatsalaswamy P. Study of variations in the origin of obturator artery. Indian Journal of Vascular and Endovascular Surgery. 2016 Oct 1;3(4):131.

[11]. Maneesha S, Tripta S, Richhpal S, Kaur AA. Variations of obturator artery in man. Anat Physiol. 2012;2(105):2161-0940.

[12]. Fitzerald MJT. Human Embryology. New York: Harper International; 1978:38-56.

How to cite this article:

Basavaraj Dhabale, Santosh Kumar Mulage. A CADAVERIC STUDY OF VARIABILITY IN THE ORIGIN OF OBTURATOR ARTERY. Int J Anat Res 2018;6(2.1):5096-5100. DOI: 10.16965/ijar.2018.124 